\title{
Pemanfaatan Perbedaan Temperatur Pada Main Engine Cooling System Sebagai Energi Alternatif Untuk Pembangkit Listrik Di Kapal
}

\author{
Teguh Julianto, Indra R. Kusuma, dan Juniarko Prananda \\ Jurusan Teknik Sistem Perkapalan, Fakultas Tekologi Kelautan, Institut Teknologi Sepuluh Nopember (ITS) \\ Jl. Arief Rahman Hakim, Surabaya 60111 Indonesia \\ e-mail: teguh.julianto.7@gmail.com, irkusuma97@gmail.com
}

\begin{abstract}
Abstrak-Dari 100 persen bahan bakar yang masuk ke dalam mesin kapal, hanya sekitar 40 persem yang dikonversi menjadi daya. Sedangkan 30 persen panas dilepas menuju sistem pendingin (cooling system) dan sisanya menjadi gas buang (exhaust). Energi panas yang terbuang tersebut bisa dimanfaatkan menjadi energi listrik. Perbedaan temperatur antara air panas yang keluar dari mesin kapal dan air laut yang digunakan sebagai pendingin dapat dikonversi menjadi energi listrik dengan menggunakan thermoelectric. Besarnya daya listrik yang dihasilkan tergantung pada besarnya perbedaan temperatur dan jumlah thermoelectric yang dipasang.Tujuan dari penelitian ini adalah untuk menemukan metode yang tepat guna memanfaatkan energi panas yang terbuang pada sistem pendingin mesin. Metode yang digunakan adalah dengan melakukan kajian pustaka serta analisa ekperimen menggunakan prototype. Hasil penelitian berdasarkan keluaran jacket water mesin Wartsila 6L20 sebesar $91{ }^{\circ} \mathrm{C}$ yang harus didinginkan dengan air laut bertemperatur $30^{\circ} \mathrm{C}$ didapatkan daya sebesar 32,4 Watt dari 12 thermoelectric yang dipasang. Dengan penyerapan energi sebesar 0,4 persen. Dengan begitu, masih banyak potensi energi yang masih bisa diserap untuk diubah menjadi energi listrik. Sehingga, dari penelitian tersebut dapat disimpulkan bahwa panas yang terbuang dari mesin yang dianggap tidak berguna dapat diubah menjadi energi listrik yang ramah lingkungan.
\end{abstract}

Kata Kunci- Daya, Pendingin, Penyerapan, Temperature, Thermoelectric

\section{PENDAHULUAN}

$\mathrm{K}$ ONSUMSI energi cukup besar terjadi di dunia perkapalan. Pada kapal dibutuhkan sebuah main untuk menggerakkan kapal. Selain itu, kondisi kapal yang dinamis menuntut kapal untuk bisa menyediakan sumber energi listrik sendiri. Pada kapal sumber listrik di hasilkan oleh mesin diesel generator. Mesin diesel generator bekerja untuk memenuhi suplai listrik ke semua sistem kapal selama kapal beroperasi. Penggunaan bahan bakar minyak pun tak bisa dihindarkan sebagai penggerak mesin diesel tersebut. Dengan kondisi kapal yang beroperasi dalam waktu yang lama, maka konsumsi bahan bakar minyakpun begitu besar.

Sedangkan efisiensi thermal yang ada pada sebuah motor diesel pun secara umum masih berlangsung cukup rendah. Dari 100 persen bahan bakar yang masuk, hanya 40 persen saja yang berubah menjadi daya untuk menggerakkan kapal. Sementara 30 persen berubah menjadi gas buang (exhaust), dan 30 persen menuju pendingin (coolant) [1]. Air keluar dari main engine dengan suhu 91 Celcius. Sedangkan untuk bersirkulasi masuk kembali ke main engine dibutuhkan temperatur sekitar $80^{\circ} \mathrm{C}$ Celcius. Sehingga air tersebut perlu didinginkan menggunakan air laut yang bertemperatur sekitar 25-35 ${ }^{0} \mathrm{C}$ pada sistem pendingin [2]. Dari 100 persen bahan bakar yang masuk ke main engine, sebanyak 15-30 persen berubah menjadi panas yang mengalir menuju sistem pendingin. Pada sistem pendingin tersebut terdapat perbedaan gradient suhu yang cukup signifikan. Air pendingin yang berasal dari sea water bekerja untuk mendinginkan air panas yang berasal dari main engine. Perbedaan gradient suhu $(\Delta \mathrm{T})$ pada sistem pendingin inilah sangat berpotensi untuk menghasilkan energi listrikdengan menggunakan thermoelectric [3].

Sementara itu, sistem pendingin merupakan sistem yang terdiri dari beragam komponen untuk melakukan fungsi sebagai pendingin dari mesin, baik mesin induk maupun mesin bantu sehingga sistem tersebut sukses berjalan kontinu sesuai desain yang diinginkan. Selain sebagai pendingin engine, cooling system ini juga untuk mendinginkan LO, scavange air, dan jacket water. 


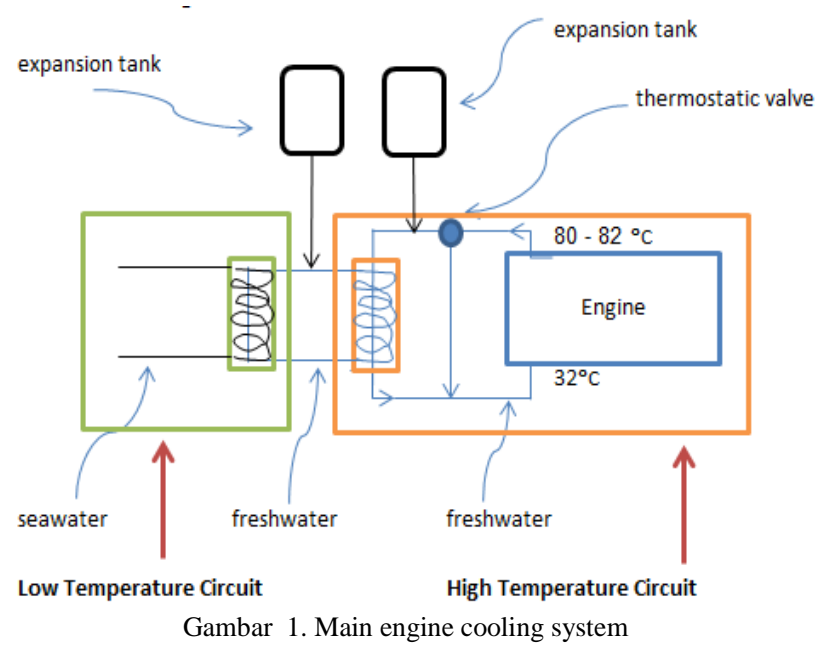

Pada umumnya, pendingin di mesin kapal menggunakanheat exchanger. Heat exchanger merupakan alat yang digunakan untuk memindahkan panas dari sistem ke sistem lain tanpa perpindahan massa dan bisa berfungsi sebagai pemanas maupun sebagai pendingin. Biasanya, medium pemanas dipakai adalah air yang dipanaskan sebagai fluida panas dan air biasa sebagai air pendingin (cooling water). Penukar panas dirancang sebisa mungkin agar perpindahan panas antar fluida dapat berlangsung secara efisien. Pertukaran panas terjadi karena adanya kontak, baik antara fluida terdapat dinding yang memisahkannya maupun keduanya bercampur langsung (direct contact). Air panas yang keluar dari main engine dengan suhu $80-90^{\circ} \mathrm{C}$ akan didinginkan menggunakan heat exchanger sebelum air tersebut kembali disirkulasikan menuju engine. Pendinginan tersebut dilakukan hingga suhu sekitar $80{ }^{\circ} \mathrm{C}$ atau tergantung pada spesifikasi engine yang digunakan. Proses pendinginan pada heat exchanger menggunakan media air (air laut) guna mempercepat perubahan suhunya. Sehingga akan terjadi perbedaan temperatur yang cukup signifikan saat proses pendinginan di heat exchanger. Perbedaan temperatur tersebut sangat berpotensi untuk dimanfaatkan menjadi energi listrik dengan menggunakan thermoelectric.

Jika material thermoelektrik dialiri listrik, panas yang ada di sekitarnya akan terserap. Material thermoelectric merupakan material yang bisa mengu Material logam (biasanya semi konduktor) yang tersambung berada di lingkungan dengan dua temperature berbeda, maka di material tersebut akan mengalir arus listrik atau gaya gerak listrik [4].

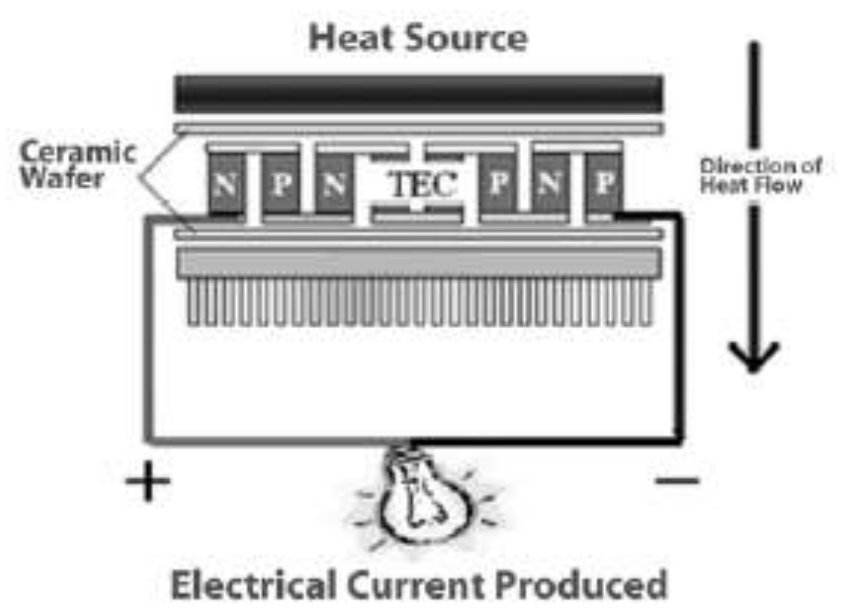

Gambar 2. Struktur Thermoelectric [5]

Daya yang dihasilkan oleh thermoelectric sangat bergantung pada perbedaan temperatur yang didapatkan. Karena panas buang mesin bersifat fluktuatif, nilai daya yang dihasilkan juga dapat berubah-ubah. Namun, selama mesin dinyalakan nilai dayanya akan terus ada. Hal penting lainnya adalah bahwa daya keluaran adalah hasil perbedaan temperatur ke dua sisi modul termoelektrik. Artinya bukan berarti bagaimana mendapatkan jumlah kalornya, akan tetapi seberapa besar perbedaan temperatur yang didapatkan. Semua ini berhubungan dengan efisiensi dari termoelektrik itu sendiri. Jika perbedaan temperaturnya semakin besar, maka daya keluarannya juga makin besar, hingga titik maksimum efisiensi peltier tersebut. [6]Perbedaan temperatur yang makin besar antara sisi panas dan sisi dingin modul akan menghasilkan tegangan dan arus yang lebih besar. Modulmodul termoelektrik dapat juga disambungkan bersama baik secara seri ataupun pararel seperti baterai untuk menghasilkan tegangan atau arus listrik. Tiap modul mampu menghasilkan tegangan rata-rata $1-2 \mathrm{~V}$ DC dan bahkan sampai $5 \mathrm{~V}$ DC bergantung pada variasi delta temperaturnya, tetapi umumnya satu modul termoelektrik menghasilkan 1,5-2V DC [7].

Tujuan dari penelitian ini adalah untuk mengetahui desain sistem yang tepat sehingga bisa didapatkan daya sebesar mungkin dengan memanfaatkan pendingin main engine. Selain itu adalah pengaruh perbedaan temperature dan laju aliran terhadap daya yang dihasilkan dengan menggunakan thermoelectric.

\section{METODE PENELITIAN}

Penyusunan metodologi ini dimaksud untuk mencapai tujuan penelitian yang telah disusun dan ditetapkan sebagaimanaterlihat pada diagram alir berikut: 


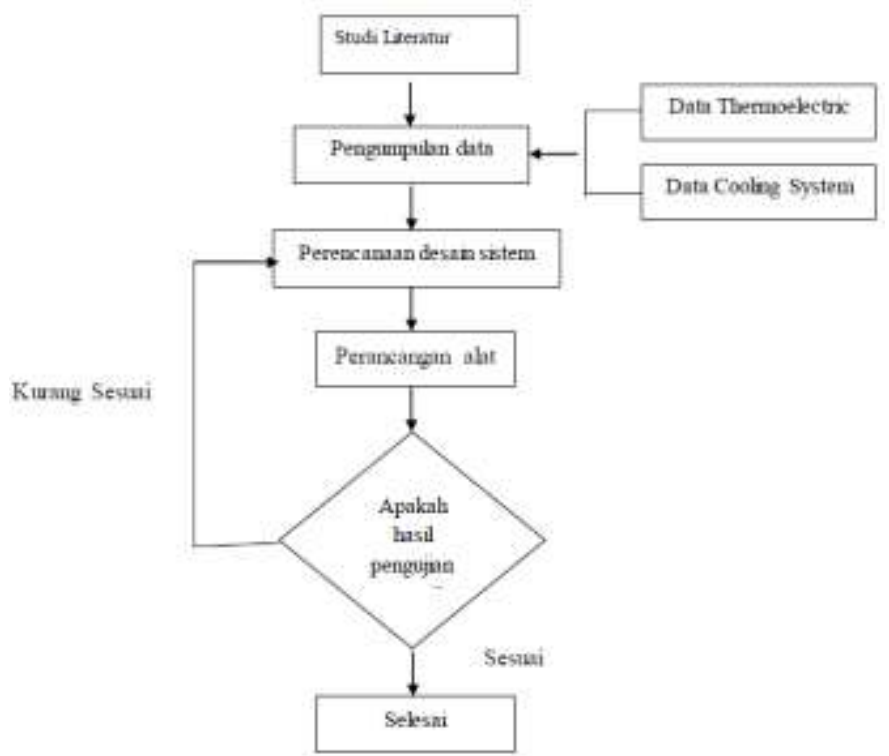

Gambar 3. Metode Penelitian

Penelitian ini dimulai dengan studi literatur dari buku-buku maupun jurnal yang telah ada. Kemudian dilakukan pengumpulan data yang kemudian dilanjutkan dengan konsep desain pembangkit listrik dengan menggunakan sistem pendingin. Perancangan desain sistem ini difokuskan tentang bagaimana bisa menghasilkan perbedaan temperatur sebesar mungkin pada prototype sehingga akan bisa didapat daya yang lebih besar pula. Proses pengambilan data dilakukan dengan menggunakan eksperimen pada sebuah prototype yang merupakan skema kecil dari sistem pendingin di kapal. Prototype ini terbuat dari bahan aluminium yang dibentuk seperti box yang didalamnya telah dipasang thermoelectric.

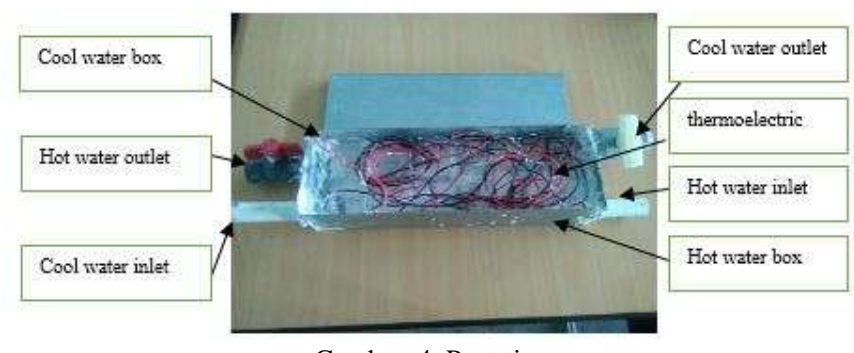

Gambar 4. Prototipe

Gambar 4 merupakan prototype alat yang digunakan untuk mengonversi energi panas menjadi listrik pada sistem pendingin. Pada alat ini terdapat 12 buah thermoelectric yang dirangkai secara seri dan diletakkan di tengah-tengah box di antara box tempat mengalirnya air panas dan air dingin. Percobaan pertama adalah dengan melakukan variasi temperatur pada bejana yang digunakan untuk memanaskan air. Pemanasan air dilakukan dengan menggunakan electric heater hingga temperature yang ditentukan. Kemudian dialirkan melalui katub hot water inlet. Sedangkan air dinginnya dialirkan menggunakan pompa dengan melalui katub cold water inlet. Setelah keduanya mengalir, maka akan diketahui tegangan dan arus yang dihasilkan. Percobaan kedua adalah dengan mengvariasikan bukaan katub. Bukaan katub tersebut akan memberikan debit yang berbeda-beda.

\section{HASIL PENELITIAN}

Pengujian alat dilakukan sampai temperatur air panas dan dingin dalam kondisi stabil. Dalam percobaan ini, yang menjadi parameter utama dalam pengambilan data adalah temperatur. Dalam percobaan tersebut, tegangan maksimal (pada $\left.\mathrm{Th}=95{ }^{\circ} \mathrm{C}\right)$ yang dihasilkan oleh 12 thermoelectric yang dirangkai seri adalah 20 Volt. Sedangkan arusnya 2 ampere. Sehingga daya dengan menggunakan rumus $\mathrm{P}=\mathrm{V} \times \mathrm{I}$, maka akan didapat daya sebesar 40 Watt.

Data dari hasil dari penelitian tersebut dapat dilihat pada gambar 5.

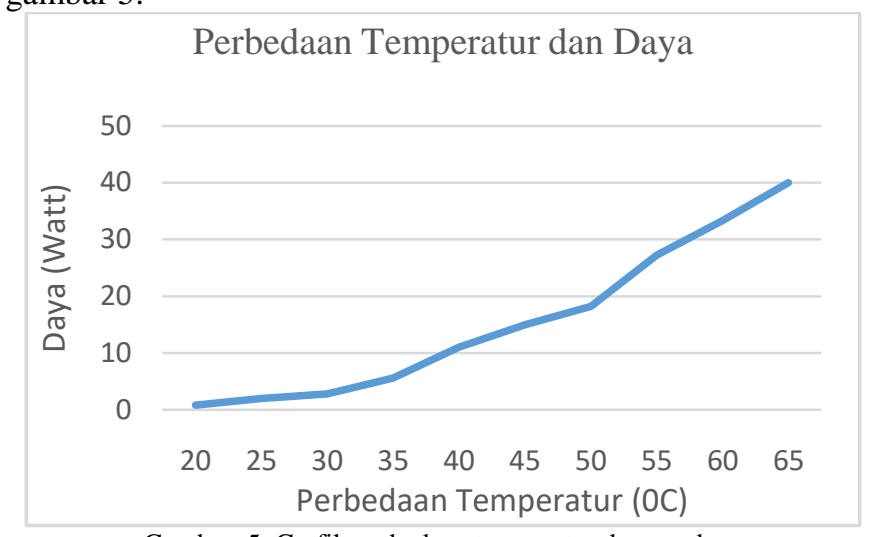

Daya yang dihasilkan oleh thermoelectric sangat bergantung pada perbedaan temperatur yang didapatkan. Karena panas buang mesin bersifat fluktuatif, nilai daya yang dihasilkan juga dapat berubah-ubah. Namun, selama mesin bekerja nilai dayanya akan terus ada. Hal penting lainnya adalah bahwa daya keluaran adalah hasil perbedaan temperatur ke dua sisi modul termoelektrik. Artinya bukan berarti bagaimana mendapatkan jumlah kalornya, akan tetapi seberapa besar perbedaan temperatur yang didapatkan. Semua ini berhubungan dengan efisiensi dari termoelektrik itu sendiri. Jika perbedaan temperaturnya semakin besar, maka daya keluarannya juga makin besar, hingga titik maksimum efisiensi peltier tersebut. Oleh karena itu, konsep desain daripada prototype ini adalah bagaimana menghasilkan perbedaan temperature sebesar mungkin di antara kedua sisi thermoelectric tersebut.

Table 1. Data Hasil Penelitian

\begin{tabular}{|c|c|c|c|c|c|c|c|c|c|}
\hline No & $\begin{array}{l}\text { Kondisi } \\
\text { valve }\end{array}$ & $\begin{array}{c}\mathrm{T} \\
\text { water } \\
\text { inlet } \\
\text { (oC) }\end{array}$ & $\begin{array}{c}\mathrm{T} \\
\text { water } \\
\text { outlet } \\
\text { (OC) }\end{array}$ & $\begin{array}{l}\text { Debit } \\
\text { (L/s) }\end{array}$ & $\begin{array}{c}\text { waktu } \\
\text { (s) }\end{array}$ & $\begin{array}{l}V \\
(L)\end{array}$ & $\begin{array}{l}\text { massa } \\
\text { (gr) }\end{array}$ & $\begin{array}{l}\text { tegangan } \\
\text { (V) }\end{array}$ & $\begin{array}{l}\text { Arus } \\
\text { (A) }\end{array}$ \\
\hline 1 & $\begin{array}{l}\text { valve } \\
\text { tertutup } \\
\text { valve } \\
\text { terbuka }\end{array}$ & 90 & 78 & 0 & 0 & 0 & 0 & 0 & 0 \\
\hline 2 & $\begin{array}{l}\text { setengah } \\
\text { valve } \\
\text { terbuka }\end{array}$ & 90 & 78 & 0.05 & 18 & 0.9 & 900 & 14 & 1.8 \\
\hline 3 & penuh & 90 & 78 & 0.125 & 7.2 & 0.9 & 900 & 14 & 1.8 \\
\hline
\end{tabular}


Dari tabel 1, dapat dilihat bahwa debit air yang mengalir menuju prototype tidak begitu berpengaruh pada tegangan dan arus yang dihasilkan. Melainkan berpengaruh pada lamanya waktu pengisian yang dibutuhkan air untuk memenuhi prototype. Dalam percobaan telah dilakukan tiga variasi percobaan yang berbeda. Yang menjadi variabel bebas adalah bukaan katub. Baik katub inlet maupun outlet. Bukaan katub tersebut berpengaruh pada debit air. Sementara debit air juga berpengaruh pada laju aliran massa dan lamanya waktu pengisian. Tetapi tidak pada daya yang dihasilkan. Pada dasarnya, tegangan dan arus akan dihasilkan jika terjadi perbedaan temperature antara sisi panas dan sisi dingin thermoelectric. Air panas yang mengalir ke dalam prototipe akan bisa menghasilkan daya jika sudah bersentuhan dengan thermoelectric. Sementara dalam percobaan tersebut, air panas akan bisa menyentuh thermoelectric jika air sudah bisa memenuhi prototype. Hal itu disebabkan karena desain dari penempatan thermoelectric diletakkan di bagian atas dari kotak penyimpan air panas.

Volume air panas yang dibutuhkan untuk masuk dalam prototype yaitu $900 \mathrm{~mL}$. Jika debit air sebesar $0.05 \mathrm{~L} / \mathrm{s}$ (katub setengah terbuka), maka waktu yang diperlukan untuk memenuhi prototype adalah 18 detik. Sementara jika debit air sebesar $0.125 \mathrm{~L} / \mathrm{s}$ (katup terbuka penuh), maka waktu yang diperlukan adalah 7,2 detik.

Jika debit semakin besar, maka waktu yang dibutuhkan untuk memenuhi volume prototipe akan semakin cepat. Lama waktu pengisian tersebut akan berpengaruh pada waktu yang dibutuhkan oleh prototype untuk menghasilkan dayanya.

\section{Perhitungan Energi yang Terbuang}

Jika dibahas lebih lanjut, debit dari aliran air akan berpengaruh pada besarnya energi panas yang terbuang per satuan waktunya. Energi panas yang terbuang dari prototype tersebut dapat dihitung dengan rumus berikut:

Di mana :

$$
q=m x C p x d T
$$

$\mathrm{q}$ = Energi panas yang terbuang (Joule)

$\mathrm{m}=$ Massa $\quad(\mathrm{Kg})$

$\mathrm{Cp}=$ Kalor jenis $\quad\left(\mathrm{J} / \mathrm{Kg}^{0} \mathrm{C}\right)$

$\mathrm{dT}=$ Perbedaan temperature pada input dan output

$\left({ }^{0} \mathrm{C}\right)$

Dengan menggunakan rumus tersebut, maka perhitungan energi yang terbuang adalah

- Energi yang terbuang saat kondisi katub setengah terbuka

Diketahui:

$$
\begin{array}{ll}
- & \text { Debit }(\mathrm{Q})=0.125 \mathrm{~L} / \mathrm{s}=0.125 \times 10^{-3} \mathrm{~m}^{3} / \mathrm{s} \\
- & \text { Cp air }=4200 \mathrm{~J} / \mathrm{kg}^{0} \mathrm{C} \\
- & \mathrm{T}_{\text {input }}=91{ }^{\circ} \mathrm{C} \\
- & \mathrm{T}_{\text {output }}=78{ }^{0} \mathrm{C}
\end{array}
$$

Maka energi yang terbuang tiap satuan waktu,

$\mathrm{q}=\mathrm{m} \times \mathrm{Cp} \times \mathrm{dT}$

$\mathrm{q}=(\rho . Q . \mathrm{t}) \times \mathrm{Cp} \times\left(\mathrm{T}_{\text {input }}-\mathrm{T}_{\text {output }}\right)$

$\frac{q}{t}=\rho . Q \times C p \times\left(\mathrm{T}_{\text {input }}-\mathrm{T}_{\text {output }}\right)$

$\frac{q}{t}=1000 \mathrm{~kg} / \mathrm{m}^{3} 0.125 \times 10^{-3} \mathrm{~m}^{3} / \mathrm{s} \times 4200 \mathrm{~J} / \mathrm{kg}^{0} \mathrm{C} \times$

$(91-78)^{\circ} \mathrm{C}$

$$
\frac{q}{t}=6825 \mathrm{~J} / \mathrm{s}
$$

Dalam kasus ini, sebagaimana dalam rumus

$$
q=m x C p x d T,
$$

yang paling berpengaruh pada energi yang terbuang adalah massa (m). Massa air tersebut sangat dipengaruhi oleh debit dari laju aliran massa (gr/s). Sementara laju aliran massa juga dipengaruhi oleh debit (Q) air yang mengalir. Artinya, semakin besar debitnya, maka semakin besar pula laju energi yang terbuang tiap satuan waktunya.

Simulasi ini juga sesuai dengan apa yang terjadi dalam proses pembakaran di engine. Performa engine akan berpengaruh pada energi yang digunakan sekaligus energi yang dibuang. Semakin sering dan semakin besar power yang dihasilkan dalam kerja engine, maka massa air yang mengalir menuju sistem pendingin juga akan semakin besar. Jika suatu engine bekerja terus menerus dengan putaran yang tinggi, maka energi yang terbuang pun juga akan semakin besar. Besarnya energi yang terbuang itu sangat potensial untuk diserap dan dikonversi menjadi energi yang lebih berguna.

\section{Perhitungan Energi yang Diserap}

With using the prototype, the energy is wasted as heat can be converted into useful electrical energy. The quantity of energy that can be absorbed to be converted into electricity could be known in a matter of following:

Diketahui:

$$
\begin{array}{ll}
\text { a. } & \text { Power }(\mathrm{P})=32,4 \mathrm{Watt} \\
\text { b. } & \text { Energy }\left(\frac{q}{t}\right)=6825 \mathrm{~J} / \mathrm{s}
\end{array}
$$

Then the energy absorbed is

the energy absorbed $=\frac{\mathrm{P}}{\mathrm{q} / \mathrm{t}}$

the energy absorbed $=\frac{32,4}{6825} \times 100 \%$

the energy absorbed $=0,4 \%$

Penyerapan energi untuk diubah menjadi listrik dengan menggunakan prototipe ini adalah sebesar 0,4 persen. Hal ini membuktikan bahwa metode konversi energi dengan menggunakan termoelektrik pada sistem pendingin masih sangat potensial untuk bisa menghasilkan energi listrik yang lebih besar. Prosentase yang relatif masih kecil itu dikarenakan masih banyak energi yang masih belum bisa diubah menjadi listrik oleh termoelektrik. Jumlah temperatur yang diserap oleh prototype ini adalah perbandingan antara temperatur saat masuk dan saat keluar dari prototipe. Temperatur yang masuk sebesar $91{ }^{\circ} \mathrm{C}$, sedangkan yang keluar adalah $78{ }^{\circ} \mathrm{C}$. Sehingga, ada temperatur sebesar $13{ }^{\circ} \mathrm{C}$ yang hilang saat melewati prototipe. Artinya, temperature sebesar itulah yang diserap oleh prototipe. Baik itu oleh termoelektrik, maupun bahan dari prototipe tersebut. Hal itulah yang menyebabkan prosentase penyerapan energi yang dikonversi menjadi listrik masih relatif kecil. Energi yang terbuang lebih banyak diserap oleh dinding-dinding prototipe dan pipa-pipa instalasi. Sedangkan yang diserap oleh termoelektrik masih sedikit. Hal itu terjadi karena luasan permukaan termoelektrik yang bersentuhan jauh lebih kecil dari jumlah luasan permukaan dinding-dinding prototipe. Prosentase yang terserap akan menjadi lebih besar jika desain prototipe tersebut bisa menampung lebih banyak termoelektrik. Karena 
semakin banyak termoelektrik yang dipasang pada dindingdinding prototipe maka akan semain banyak pula luasan dari termoelektrik yang bersentuhan langsung dengan air panas. Sehingga akan didapat energi listrik yang lebih besar.

Aplikasi di Kapal

Hasil penelitian ini coba diaplikasikan pada sistem pendigin pada mesin induk Wartsila 6L20. Berikut merupakan data dari sistem pendingin pada mesin wartsila 6L20:

Fresh Water flow at $100 \%$ load $=30 \mathrm{~m}^{3} / \mathrm{h}=8,3 \times 10^{-3} \mathrm{~m}^{3} / \mathrm{s}$

Pressure drop over engine $=0,12$ bar

Temperature after engine $\left(T_{\text {input }}\right)=91{ }^{\circ} \mathrm{C}$

Temperature before engine $\left(T_{\text {output }}\right)=83{ }^{\circ} \mathrm{C}$

Dari data tersebut, dapat dihitung laju aliran energi panas yang terbuang menuju pendingin yang bisa dikonversi menjadi energi listrik melalui perhitungan berikut,

$$
\begin{aligned}
& \mathrm{q}=\mathrm{m} \times \mathrm{Cp} \times \mathrm{dT} \\
& \mathrm{q}=(\rho \cdot \mathrm{Q} . \mathrm{t}) \times \mathrm{Cp} \times\left(\mathrm{T}_{\text {input }}-\mathrm{T}_{\text {output }}\right) \\
& \frac{q}{t}=\rho \cdot \mathrm{Q} \times \mathrm{Cp} \times\left(\mathrm{T}_{\text {input }}-\mathrm{T}_{\text {output }}\right) \\
& \frac{q}{t}=1000 \mathrm{~kg} / \mathrm{m}^{3} \times 8,3 \times 10^{-3} \mathrm{~m}^{3} / \mathrm{s} \times 4200 \mathrm{~J} / \mathrm{kg}^{0} \mathrm{C} \times(91- \\
& 83)^{0} \mathrm{C} \\
& \frac{q}{t}=278.880 \mathrm{~J} / \mathrm{s}
\end{aligned}
$$

Dengan perhitungan tersebut, maka akan ada potensi energi panas yang bisa dikonversi menjadi energi listrik sebesar $278.880 \mathrm{~J} / \mathrm{s}$. Besarnya energi listrik yang dihasilkan juga akan tergantung pada jumlah maksimal dari thermoelectric yang dipasang dalam kotak/box pengkonversi ini. Box ini akan dipasang pada sistem pendingin main engine dan akan ditempatkan sebelum cooler. Jadi, sebelum air panas didinginkan oleh cooler, air tersebut terlebih dahulu masuk ke box dan akan dimanfaatkan menjadi energi listrik. Besarnya alat juga disesuaikan dengan space yang ada di kamar mesin. Semakin luas space dari kamar mesin, maka semakin besar pula alat yang bisa dibuat. Misalnya, kamar mesin tersebut, ada space seluas $1 \mathrm{~m}^{2}$ yang bisa digunakan untuk meletakkan box konversi. Sehingga akan dibuat box dengan luas $1 \mathrm{~m}^{2}$.

Air panas akan menuju box konversi terlebih dahulu kemudian mengalir menuju cooler. Sedangkan air dingin (sea water) masuk melalui sea chest dan dipompa menuju box konversi. Sistem perpipaan untuk air dingin ini menggunakan sistem yang terpisah dari sistem pendingin. Hal itu dilakukan agar tidak mengganggu kerja dari sistem pendingin itu sendiri.

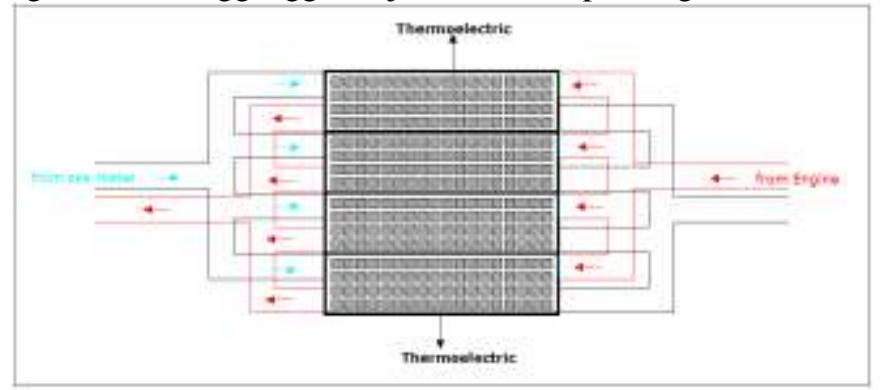

Gambar 6. Penempatan thermoelectric pada box

Sebagaimana terlihat pada gambar 6. desain dari box dibuat memanjang. Box air panas berdimensi $95 \mathrm{~cm} \times 25 \mathrm{~cm} \times 15$ $\mathrm{cm}$. untuk sebuah sisi box dengan luas $95 \mathrm{~cm} \times 25 \mathrm{~cm}$ bisa terpasang 72 keping thermoelectric. Jika terdapat dua sisi yang akan dipasang, maka masing-masing box bisa menampung 144 keping thermoelectric. Dalam kamar mesin yang dirancang sebagaimana gambar 4.18, terdapat space seluas 1 $\mathrm{m}^{2}$. Sehingga bisa tersusun 4 box yang mampu menampung total 576 keping thermoelectric. Sistem perpipaan dibuat bercabang dan kemudian masuk ke masing-masing box. Hal itu bertujuan agar temperatur pada keempat box tersebut sama besar.

Berdasarkan data eksperimen (lihat tabel 4.1), 12 keping thermoelectric bisa menghasilkan daya sebesar 40 watt. Maka daya yang bisa didapat bisa dihitung sebagaimana berikut:

12 keping ( 1 bank $)=40$ watt

Jumlah bank $=\frac{\text { jumla hthermoelectric }}{12}$ $=\frac{576}{12}=48$ bank.

Daya yang dihasilkan $=$ jumlah bank $\mathrm{x} 40$ watt $=48 \times 40$

$$
=1920 \mathrm{Watt}=1,92 \mathrm{Kw}
$$

Daya 1,92 Kw sudah cukup untuk digunakan pada lampulampu penerangan di kamar mesin.

\section{KESIMPULAN}

Air panas yang terbuang dari main engine yang terbuang menuju sistem pendingin sangat berpotensi untuk menghasilkan energi listrik. Hal itu sangat tergantung pada bagaimana desain dari pada alat dan penempatan thermoelectric. Desain yang tepat adalah dengan memberikan kontak langsung antara air panas atau dingin dengan thermoelectric. Sehingga temperatur air panas dari mesin tidak jauh berbeda dengan yang diserap thermoelectric.

\section{UCAPAN TERIMA KASIH}

Penulis T.J. .mengucapkan terima kasih kepada Direktorat Pendidikan Tinggi, Departemen Pendidikan dan Kebudayaan Republik Indonesia yang telah memberikan dukungan finansial melalui Beasiswa Bidik Misi tahun 2012-2016.

\section{DAFTAR PUSTAKA}

[1] Guojin, Chen. "Study on Air Intake and Cooling System for Marine Diesel Engine". Telkomnika Indonesian Journal of Electrical Engineering, ;2014:. 998-1004

[2] Wartsila. "Wartsila 20 Product Guide". Wärtsilä. Finlandia

[3] Lutfi, Achmad Saifuddin. "Prototype Pembangkit Daya Termoelektrik Pada Sistem Pendingin Engine Kapal Untuk Pengisian Baterai Starting Generator-Set”. Institut Teknologi Sepuluh Nopember; 2015

[4] G. Min, D.M. Roe, Handbook of thermoelectrics, Peltier devices as generator, CRC Press LLC, Florida, 1994, p.479.

[5] Putra, Nandy. (2009). "Potensi Pembangkit Daya Termoelektrik untuk Kendaraan Hibrid" Makara Teknologi, Vol. 13, No. 2, 53-58.

[6] W. He dkk. "Optimization Design Method Of Thermoelectric Generator Based On Exhaust Gas Parameters For Recovery Of Engine Waste Heat" Energy $91 ; 2015: 1-9$

[7] Wirawan, Rio. Analisa Penggunaan heat pipe pada thermoelectric generator. Universitas Indonesia. 2012 